\title{
EPIDEMIOLOGY, DIAGNOSIS AND PUBLIC HEALTH IMPORTANCE OF TRICHINELLOSIS
}

\author{
Muluken Yayeh, Gemechis Yadesa, Mareye Erara, Shumye Fantahun, Alemseged Gebru and Mastewal Birhan \\ University of Gondar, Collage of Veterinary Medicine and Animal Sciences, Ethiopia \\ Email: yayehmulu@gmail.com \\ Supporting Information
}

\begin{abstract}
Trichinellosis is a parasitic zoonosis caused by Trichinella following ingestion of raw or under cooked meat containing Trichinella larvae. Nematode worms of the genus Trichinella are one of the most prevalent zoonotic pathogens in the world. The parasite infects domestic and wild animals and has a worldwide distribution. The life cycle of the parasite consists of a domestic cycle in mainly pigs and a sylvatic cycle in a wider range of animals such as bears and wild boar. Humans become infected after eating raw or undercooked meat from domestic pigs, horses or game containing Trichinella larvae. There are twelve genotypes within the genus Trichinella, eight of which have been designated as species from which T.spiralis is the most pathogenic one. Host animals ingesting even high numbers of Trichinella larvae from infectious meat will not develop clinical symptoms. In humans, the clinical picture is usually illustrated by an intestinal stage within the first or second week after infection and later muscular stage with periorbital oedema, myalgia or muscle weakness as the major symptoms. The severity of the clinical course depends firstly on parasitic factors, such as the species implicated and the number of infective larvae ingested, and secondly on host factors, such as sex, age, and immune status. In practice, treatment with anthelmintics and immunosuppressive drugs is used only with human patients, not with animals. Trichinella infection in humans is strongly associated with the consumption of raw or undercooked meat; thus, cultural factors such as traditional dishes based on raw or undercooked meat or meat-derived products.
\end{abstract}

Keyword: Human, Parasite, Pig, raw meat, Trichinellosis; Zoonosis

\section{INTRODUCTION}

Parasitic zoonosis includes both helminthic and protozoan infections. Amongst one thousand five hundred known infectious agents for human being, 287 are helminths (Chomel et al., 2008). Helminths are complex eukaryotic organisms with large genomes and complex multistage life cycles that involve numerous hosts (Hewitson et al., 2009). Nematode worms of the genus Trichinella are one of the most widespread zoonotic pathogens in the world. Infection by Trichinella species has been identified in domestic and/or wild animals of all continents, with the exception of Antarctica, where there is no record of the parasite (Murrell, 2006).

Clinical signs of trichinellosis are not generally recognised in animals, and its main importance is as a zoonosis. Trichinosis is a food-borne zoonotic disease caused by Trichinella species. Trichinellosis in humans is caused by eating raw or undercooked meat from Trichinella-infected food animals or game (Gajadhar et al., 2006). Until recently, all Trichinella infections occurring in animals and humans were attributed to Trichinella spirals. Today, eight species (T.spiralis, T.nativa, T.britovi, T.pseudospiralis, T.murrelli, T.nelsoni, T.papuae, and T.zimbabwensis and three genotypes (Trichinella T6, T8, T9) within two classes (encapsulated and non-encapsulated) are documented in this genus (Zarlenga et al., 2006).

It is a tissue-dwelling nematode acquired by the ingestion of raw or insufficiently cooked meat-products containing encapsulated larvae (La Rosa et al., 2000). The most important source of human infection worldwide is the domestic pig. In Europe, meats of horses and wild boars have played a significant role during outbreaks within the past three decades. Infection of humans occurs with the ingestion of Trichinella larvae that are encysted in muscle tissue of meat from domestic or wild animals (Bruschi et al., 2007).

Trichinella infection in the human host can be divided into two stages: an intestinal (or enteral) phase and a muscular (or parenteral or systemic) phase. Low-intensity infection can remain asymptomatic, but parasite burdens greater than a few hundred larvae can initially cause gastroenteritis associated with diarrhoea and abdominal pain approximately 2 days post infection (intestinal acute phase of disease). Subsequently, migrating larvae and their metabolites provoke an immediate reaction, with an inflammatory and allergic response, pyrexia, eyelid or facial oedema, and eosinophilia are the most prominent manifestations, occasionally complicated by myocarditis, thromboembolic disease, and encephalitis. Months or even years at the acute stage, chronic trichinellosis may yield persistent fornication, 
numbness, and excessive sweating as well as impaired muscle strength and conjunctivitis, which may continue up to 10 years post infection (Zarlenga et al., 2013).

The diagnosis of trichinellosis is based on history of consumption of potentially contaminated meat, the presence of compatible signs and symptoms, and identification of Trichinella larvae in biopsy muscle tissue or specific antibody in serum. These diagnostic methods in human host can be categorized two as direct and indirect. Under direct there are direct muscle biopsy while under indirect such as serology and molecular technique (Oivanen, 2005). Muscle biopsies are rarely performed, but they allow for the molecular identification of the Trichinella species or genotype, which is not possible with antibody testing (Oivanen, 2005).

Prompt treatment with anti-parasitic drugs can help prevent the development of trichinellosis by killing the adult worms and so preventing further release of larvae. Once the larvae have become established in skeletal muscle cells, treatment may not completely eliminate the infection and associated symptoms (Sun, 2015). Therefore, the administration of effective anthelmintic drugs at the stage of intestinal invasion or in the acute phase is critical for successful therapy. In addition, because of the predominantly zoonotic importance of infection, the main efforts in many countries have focused on the control or elimination of Trichinella from the food chain (Gottstein, 2009).

The increase in the report of Trichinellosis has been observed many eastern European countries, in Africa and Asia (Blaga et al., 2007; Azim et al., 2008). Human population growth and socioeconomic changes might have played a fundamental role in the disease emergence and spread in recent years (Macpherson, 2005). The increase in human population density, ecological change, and subsequent increased contact between humans and wild animals necessitates the importance having an update on potentially emerging diseases like trichnellosis. Therefore, the objective of this paper is to review the epidemiology and public health importance of trichinellosis.

\section{Taxonomy and Morphology of the Parasites}

\section{Taxonomy and Aetiology}

The taxonomy of the genus Trichinella has been presented with slightly varying details According to the traditional classification, the genus belongs to the phylum Nematode, roundworms, class Adenophorea, order Trichinellida, and superfamily Trichinelloidea (Oivanen, 2005). The taxonomy has recently been challenged. On the basis of results from ribosomal deoxyribonucleic acid (DNA) sequences, the present higher-level classification of Nematode will need change in to two classes, Secernentea and Adenophorea (Oivanen, 2005). Within the genus Trichinella there are twelve genotypes have been identified, eight of which have been designated as species (Gajadhar et al., 2006; Murrell et al., 2000; Pozio and Zarlenga, 2005). Trichinella spiralis was recognized in London in 1835s. The parasite being detected in an autopsy of an Italian male corpse (Oivanen, 2005).

Trichinella spiralis (T1) is distributed in temperate regions world-wide and is commonly associated with domestic pigs. It is highly infective for domestic and sylvatic swine, mice and rats, but it can also be detected in other mammalian, carnivores and horses (Pozio and Zarlenga, 2005). This species is also the most important etiological agent to cause disease in humans (Pozio, 2006). Trichinella native is the species that are very widespread in arctic and subarctic areas of the northern hemisphere (Pozio, 2000). Trichinella britovi species differs from $T$. spiralis with weak infectivity for rats, moderate resistance to freezing, moderate infectivity for swine, slow nurse cell development and low in vitro production of NBL (Malakauskas and Kapel, 2003). Trichinella nelson has occasionally been detected in pigs (Suidae) and humans, although it has very low infectivity for pigs and rats. The infectivity for humans has not been long-established (Pozio, 2001).

Trichinella murrelli this species has very low reproductive capacity in pigs and rats, low NBL production in vitro, slow nurse cell development, and low resistance to freezing (Malakauskas and Kapel, 2003). Trichinella pseudospiralis strains three genotypic isolates were identified by multiplex polymerase chain reaction from different parts of the world (PCR) test (Zerlenga et al., 1999; La Rosa et al., 2001). Trichinella papuae are where Muscle larvae are non-encapsulated and lack freezing tolerance but can survive in $+5^{\circ} \mathrm{C}$ storage for four weeks (Webster et al., 2002). Trichinella zimbabwensis is the first Trichinella strain isolated in reptiles in nature. In the laboratory, it can also infect rats, mice, pigs, baboons (Papio sp.), turtles, pythons, varans, and caimans. Its muscle larvae are non-encapsulated. It is not infective for birds, nor can it resist freezing (Pozio et al., 2004).

\section{Morphology of the Parasite}

Trichinella worms are the smallest nematode parasite of humans, they are the largest intracellular parasite and have been described as "the worm that would be virus" (Foreyt, 2013). The morphology of the parasite's oesophagus is characteristic of the Trichinellidae family, and it occupies approximately one-third of the body length and is surrounded by large cells. Adult males are 1.4 to $1.6 \mathrm{~mm}$ in length and do not have spicules, but a pair of lateral flaps is found on each side of the cloacal opening and two pairs of papillae are between them. Females' are 3 to $4 \mathrm{~mm}$ in length, and the vulva opens in the middle of the oesophageal region (Foreyt, 2013). Adult the length of $T$. spiralis NBL is $80-120 \mu \mathrm{m}$ and the diameter 5-6 $\mu \mathrm{m}$. The larvae do not increase in size until they enter the muscle cells. The larvae begin to grow in their nurse cells, reaching a length of 900-1280 $\mu \mathrm{m}$ and a diameter of 35-40 $\mu \mathrm{m}$ by 30days p.i. Trichinella adult females are a little longer and thicker than the males. Their length and diameter are 2460-3390 $\mu \mathrm{m}$ and 35-70 $\mu \mathrm{m}$, respectively, while the resulting figures for males are 1040-1300 $\mu \mathrm{m}$ and 29-32 $\mu \mathrm{m}$ (Oivanen, 2005). 

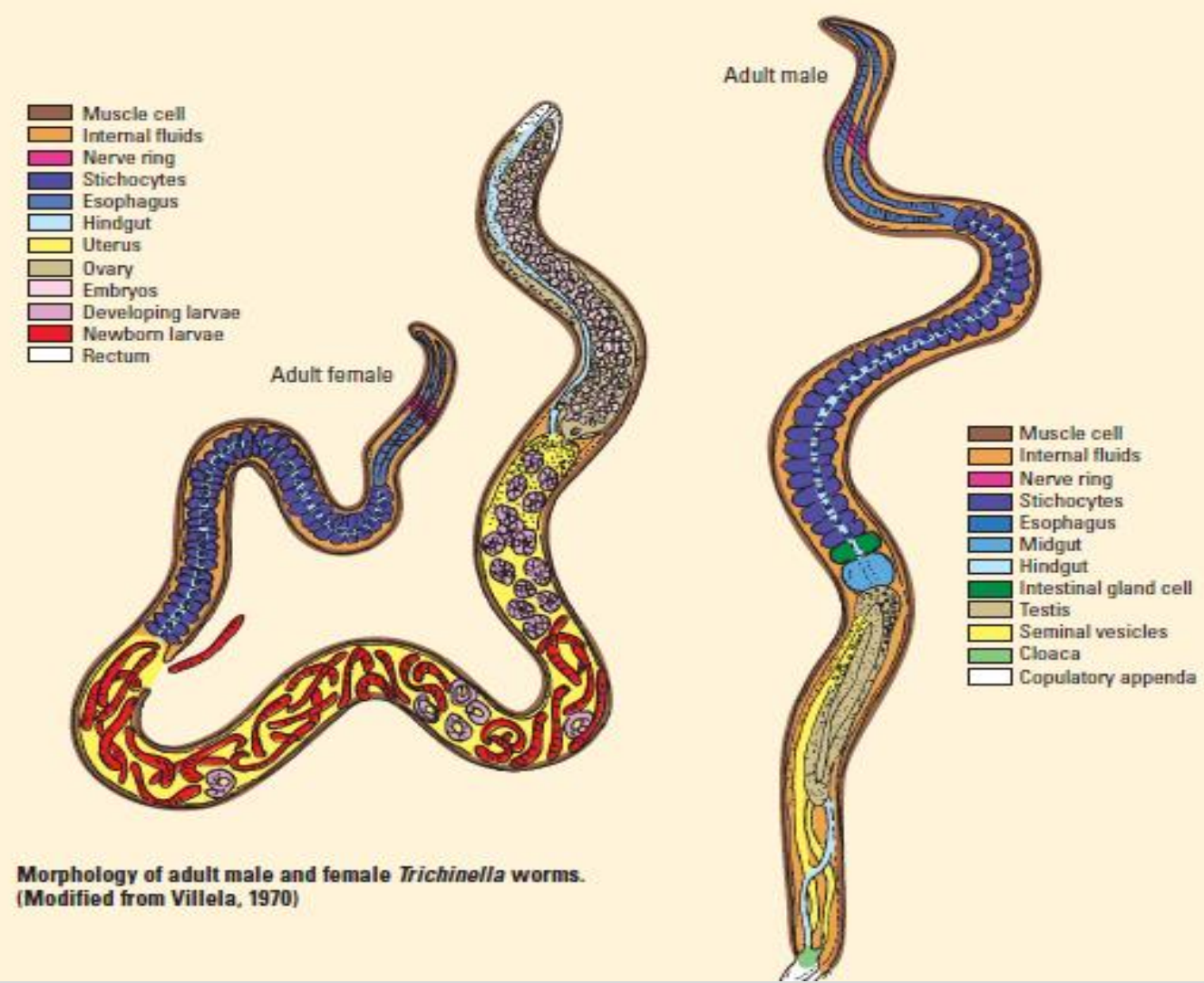

Morphology of adult male and female Trichinella worms. (Modified from Villela, 1970)

\section{Figure 1- Morphology of parasites (Foreyt, 2013)}

\section{The life cycle of the parasites}

The basic life cycle of Trichinella has been recognized since the middle of the $19^{\text {th }}$ century. This genus is unique among parasitic nematodes in that all stages of the life cycle occur within a single host. In nature, the cycle is repeated when another host animal ingests the flesh of another host containing viable muscle-stage larvae (Oivanen, 2005). The generalized life cycle of Trichinella is described in figure 2. Enteral phase; 1: muscle tissues are digested in the stomach and larvae are released; 2: larvae penetrate the intestinal mucosa of the small intestine, reach the adult stage within $48 \mathrm{~h}$ post infection, male and female mate; 3: female worm releases new born larvae in the lymphatic vessels (from the fifth day post infection onwards; the length of New born production, from one to several weeks, is under the influence of the host immunity). Parenteral phase; 4: the new born larva reach the striated muscle and actively penetrate in the muscle cell; 5: the larva grows to the infective stage in the nurse ceil (the former muscle cell); 6: after a period of time (weeks, months or years) a calcification process occurs (Pozio and Murrell, 2006).

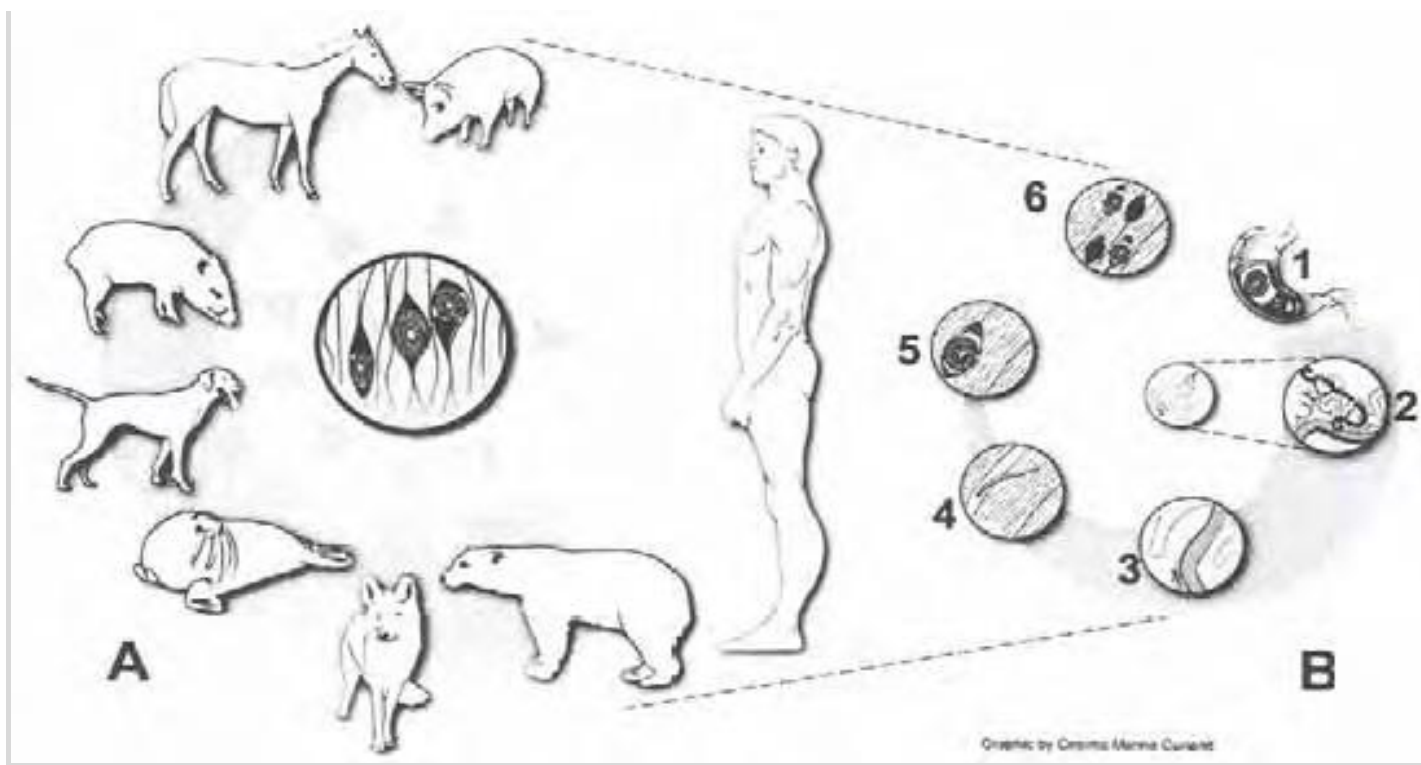

Figure 2- Trichinella sp. life cycle (Pozio and Murrell, 2006). A: main sources of Trichinella spp. infections for humans; B: Trichinella spp. cycle in the host body. 


\section{Epidemiology}

\section{Geographic distribution}

Trichinella species are present throughout most of the world in over 150 different hosts (Dick et al., 2001). In addition to $T$. spiralis, 7 other species in 4 genotypes, all of which are more commonly found in wild animals than in domestic pigs . T. spirals is cosmopolitan, this species is also the most important etiological agent to cause disease in humans (Pozio et al., 2006). In the domestic cycle, pork scraps from $T$. spiralis-infected pigs are the main source of infection for synanthropic animals (e.g., rats, horses, stray cats, and dogs). Conversely to the domestic cycle, the sylvatic cycle of $T$. spiralis includes a broad range of wild carnivores, which may, however, become the origin of a life cycle beginning into a domestic host population (Dick, 2001). Trichinella native is found in Arctic and subarctic areas of America, Asia, Europe. Trichinella genotype T6 is also found in Canada, Alaska, Rocky Mountains, and Appalachian Mountains in the United States (Pozio, 2001). Trichinella britovi is found in the temperate areas of Europe and Asia, Northern and Western Africa, Trichinella T8 is found in South Africa and Namibia. Trichinella murrelli is found in the United States and Southern Canada, Trichinella genotype T9 Japan, T. nelsoni Eastern-Southern Africa, and Trichinella genotype T12 is found in Argentina, and all the above are encapsulated while the below are non-capsulated. Those are $T$. pseudospiralis which is cosmopolitan in Palearctic, Nearctic, Ocean land (Pozio, 2001) Cosmopolitan, T. papuae is found in the Papua New Guinea, Thailand and T. zimbabwensis which is found in Zimbabwe, Mozambique, Ethiopia, South Africa (Gottstein, 2009).

\section{Host range}

The epidemiology and systematics (i.e., the study of the diversification) of this zoonosis are now recognized to involve in addition to $T$. spiralis, 7 other species in 4 genotypes, all of which are more commonly found in wild animals than in domestic pigs (Pozio, 2009). T. spiralis is found in the Domestic and sylvatic mammal, while Trichinella T8, $T$. murrelli, Trichinela genotype T9. Trichinella native and Trichinella genotype T6 is found in the sylvatic carnivores. Another species, $T$. britovi is found in the Sylvatic mammals and seldom domestic pigs, while $T$. nelson in the Sylvatic mammals. Trichinella genotype T12, T. Pseudo spiralis Sylvatic mammals and birds, domestic pigs, T. papuae Wild pigs, salt water crocodiles and T.zimbabwensis which is found in the Nile crocodiles, monitor lizards (Gottstein, 2009).

\section{Main source of infection in human}

Domestic pigs and wild boars were the major sources of Trichinella spp. infection for humans, but in recent years new infection sources, particularly from exotic hosts, have emerged (Boireau, 2000). The main source of infection in human, $T$. spiralis is found in the Domestic and sylvatic swine horses, while $T$. native is found in Bears, walruses. Others like Trichinella genotype T6 is found in Carnivores $T$. britovi is found in the Wild boars, domestic pigs horses, foxes, jackals T. zimbabwensis, Trichinella genotype T12, Trichinella genotyp T8 and Trichinella genotype T9. Trichinella murrelli in Bears, especially horses while $T$. nelson is found in the Warthogs, bush pigs Warthogs, bush pigs, T. papuae is found in the Wild pigs and T. pseudospiralis wild and domestic pigs (Gottstein, 2009).

\section{Resistance of larvae in frozen muscle}

Most of them are not resistance to the frozen muscle. Trichinella T8, T. murrelli, T.pseud ospiralis T. papuae and T.zimbabwensis, while others are $T$. spiralis resistance in horse muscles. $T$. native are resistance in carnivore muscles. Trichinella genotype T6 is resistance in carnivore muscles, $T$. britovi are resistance in carnivore and horse muscles and Trichinella genotype T12 Unknown (Gottstein, 2009). The epidemiology of trichinellosis is summarized as below in table 1.

\section{Disease ecology}

The usual source of trichinosis in humans is from eating pork products or meat from horses, dogs, or a variety of wildlife species, including wild pig, bear, walrus, and seal. Trichinella spp. is transmitted by two specific cycles, the domestic cycle and the sylvatic cycle (Dick and Pozio, 2001).

\section{Domestic cycle}

The domestic cycle is prevalent on small farms where disease control is not a primary objective in food production. Areas where infection is endemic are found throughout the world (Dupouy- Camet, 2000). The domestic cycle of transmission is primarily involves $T$. spiralis in a cycle of pig-to-pig transmission, and humans enter the cycle through eating pork. The infection can be highly pathogenic in humans. Synanthropic rats, mice, cats, dogs, and horses, as well as many wildlife species, also contribute to the cycle in many areas. Pigs maintain the cycle by eating pieces of infected meat scraps, eating infected rats or mice, biting the tails of infected pigs, cannibalizing dead pigs, ingesting feces from pigs that have recently eaten infected meat, or eating other species of infected mammals (Ortega-Pierres and others et al., 2000).

\section{Sylvatic cycle}

The sylvatic cycle of transmission predominantly involves predation, cannibalism, or scavenging behaviours of species of carnivorous wildlife. Trichinella spp. are transmitted when fresh, frozen, or decomposing carcasses or meat scraps are eaten (Dupouy-Camet, 2000). The species of Trichinella associated with the sylvatic cycle are $T$. nativa, $T$. britovi, $T$. murrelli, $T$. nelsoni, $T$. pseudospiralis, $T$. papuae and $T$. zimbabwensis. $T$. spiralis can also affect wildlife in temperate and tropical regions, but it does not survive in arctic and subarctic regions because larvae do not survive in a frozen carcass (Ortega-Pierres et al., 2000).

\section{Clinical signs}

The severity of the clinical course depends firstly on parasitic factors, such as the species involved and the number of infective larvae ingested, and secondly on host factors, such as sex, age, and immune status (Bruschi and Murrell, 
2002). The chief clinical of trichinellosis were compatible in type and frequency with the classical trichinellosis syndrome, i.e., myalgia, diarrhoea, fever, facial oedema and headaches that, after treatment, disappeared within 2-8 weeks (Dupouy-Camet and Bruschi, 2007). The clinical signs of acute trichinellosis are characterized by two phases: an enteral and a parenteral phase, corresponding to the presence of parasites in the intestine and in the circulation and/or musculature, respectively (Oivanen, 2005). The most common signs during the enteral phase of a mild infection are transient diarrhoea and nausea. However, in moderate to severe infections, the first signs are upper abdominal pain, diarrhoea or constipation, vomiting, malaise, and mild fever. The enteral phase lasts for six weeks (Kocięcka, 2000). From the second to the sixth week post infection, the enteral phase is still present, but the dominating signs arise from the parenteral phase due to the migrating larvae and their indiscriminate penetration of different tissues. During the third week post infection the symptoms intensify due to invasion of muscle cells. Characteristic signs include weakness, pain, paralysis, and photo phobia. Edema is prominent and patients may have shortness of breath. Endocarditis, myocarditis, and cardiac failure have been reported. The signs of acute illness usually diminish from the fifth or sixth week post infection onwards (Kocięcka, 2000; Oivanen, 2005).

\section{Table 1 - Epidemiology of Trichinellosis}

\begin{tabular}{|c|c|c|c|c|}
\hline Species or genotype & Geographical distribution & Host range & $\begin{array}{l}\text { Main source of infection } \\
\text { in human }\end{array}$ & $\begin{array}{l}\text { Resistance of larvae } \\
\text { in frozen muscle }\end{array}$ \\
\hline \multicolumn{5}{|l|}{ Encapsulated } \\
\hline T. spiralis & Cosmopolitan & $\begin{array}{l}\text { Domestic and sylvatic } \\
\text { mammals }\end{array}$ & $\begin{array}{l}\text { Domestic and sylvatic } \\
\text { swine horse }\end{array}$ & Yes in horse muscle \\
\hline T. nativa & $\begin{array}{l}\text { Arctic and subarctic areas of } \\
\text { America, Asia ,Europe }\end{array}$ & Sylvatic carnivores & Bears, walruses & $\begin{array}{l}\text { Yes in carnivores } \\
\text { muscle }\end{array}$ \\
\hline Trichinella genotype T6 & $\begin{array}{l}\text { Canada, Alaska, rocky } \\
\text { mountains, and Appalachian } \\
\text { Mountains in the united states }\end{array}$ & Sylvatic carnivores & Carnivores & $\begin{array}{l}\text { Yes in carnivores } \\
\text { muscle }\end{array}$ \\
\hline T. britovi & $\begin{array}{l}\text { Temperate areas of Europe } \\
\text { and Asia, northern and } \\
\text { western Africa }\end{array}$ & $\begin{array}{l}\text { Sylvatic mammals and } \\
\text { rarely domestic pigs }\end{array}$ & $\begin{array}{l}\text { Wild boar, domestic pig } \\
\text {,horse, foxes, jackal }\end{array}$ & $\begin{array}{l}\text { Yes in carnivores and } \\
\text { horse muscle }\end{array}$ \\
\hline Trichinella T8 & South Africa and Namibia & Sylvatic carnivores & None documented & No \\
\hline T. murrelli & $\begin{array}{l}\text { United states and southern } \\
\text { Canada }\end{array}$ & Sylvatic carnivores & Bears, horses & No \\
\hline Trichinella genotype T9 & Japan & Sylvatic carnivores & None documented & No \\
\hline T. nelson & Eastern-southern Africa & Sylvatic mammals & Warthogs, bush pigs & No \\
\hline Trichinella genotype T12 & Argentina & Cougars & None documented & Unknown \\
\hline \multicolumn{5}{|l|}{ Non encapsulated } \\
\hline T. pseudo spiralis & Cosmopolitan & $\begin{array}{l}\text { Sylvatic mammals and } \\
\text { birds, domestic pig }\end{array}$ & Domestic and wild pigs & No \\
\hline T. papuae & Papua new guinea, Thailand & $\begin{array}{l}\text { Wild pig, salt water } \\
\text { crocodile }\end{array}$ & Wild pig & No \\
\hline T. zimbabwensis & $\begin{array}{l}\text { Zimbabwe,Mozambique, south } \\
\text { Africa,Ethiopia }\end{array}$ & $\begin{array}{l}\text { Nile crocodiles, monitor } \\
\text { lizards }\end{array}$ & None documented & No \\
\hline
\end{tabular}

\section{Diagnosis}

\section{Direct method}

Meat inspection for the detection of Trichinella larvae is designed to prevent clinical trichinellosis in humans but not to prevent infection. The identification of Trichinella larvae in muscle samples from pigs and other animal species intended for human consumption (e.g., horses, wild boars, and bears) is limited to post-mortem inspection of carcasses. Muscle biopsy is a traditional method applied to diagnose trichinellosis. Samples are usually taken from the $M$. deltoideus. Other possible sites are the Musculus biceps brachii, Musculus gastrocnemius, M. pectoralis, M. gluteus maximus, and Musculi intercostali (Gamble, 2000). Muscle biopsy is recommended only in cases where serological results are unclear. In autopsy, the sampling site is the diaphragm (Bruschi and Murrell, 2002). Direct detection is also applied in wildlife monitoring, where indicator animals (e.g., foxes or raccoon dogs) are examined to assess the prevalence of Trichinella infection among the wildlife reservoir and the risk of introduction into domestic animals. Methods to detect Trichinella larvae in muscle samples need to be highly sensitive, and performance is greatly influenced by the sample size, the muscle type selected for sampling, and the specific method used (Nockler, 2000). In order to identify predilection sites, in particular, animal species that optimal for diagnostic investigations, several experimental studies using doses that mimic natural infections have been performed. Thus, in domestic swine, the three main predilection sites for $T$. spiralis are the diaphragm crus, the tongue, and the masseter (Gamble, 2000), and analogous results were observed in experimental T. britovi and T. pseudospiralis infection in this host species (Nockler, 2005). Some of the sampling sites recommended by the International Commission on Trichinellosis for different domestic and wild animals subjected to meat examination or epidemiological studies are summarized in Table 2. 
Table 2 - Predilection site of Trichinella larvae in different animal species

\begin{tabular}{lcc} 
Animal species & Predilection site & Aim of detection \\
\hline Domestic pig & Diaphragm, Masseter, Tongue & Meat inspection (domestic animals) \\
Horse & Tongue masseter & Meat inspection (domestic animals) \\
Wild boar & Forearm, diaphragm ,tongue & Meat inspection (game) \\
Bear & Tongue, diaphragm, masseter & Meat inspection (game) \\
Water seal & Tongue,diaphragm flipper, masseter & Meat inspection (game) \\
Fox & Tongue, forearm, diaphragm, masseter & Epidemiological studies (reservoir animal) \\
Raccoon dog & Diaphragm ,forearm, muscle, tongue & Epidemiological studies (reservoir animal) \\
\hline Source: Nockler, (2005). & &
\end{tabular}

\section{Serology}

Serology is considered to be appropriate for the surveillance and epidemiological investigations of trichinellosis in domestic animals and wildlife (Dworkin, 1996). The indirect serological diagnostic methods can be used at both antimortem and post-mortem examination for Trichinella-specific antibodies. Several conventional Sero diagnostic methods have been practiced in detecting Trichinella larvae. These include ELISA, immunofluorescence antibody test (IFAT), complement fixation test, and hemagglutination test and molecular technique (Oivanen, 2005).

\section{Enzyme Linked Immunosarbant Assay (ELISA)}

The ELISA method is relatively simple to apply, and it can be automated in Trichinella diagnostics. It is sufficiently sensitive to detect low-level infect ion (Nöckler et al., 2000). Traditionally ELISA has been applied to analyse antibodies in serum samples. According to some reports, samples of muscle juice can substitute for serum samples. This may be a practical solution if serum is unavailable. Results with muscle juice were hopeful in pigs but inconsistent in wild red foxes (Vercammen et al., 2002). However, this method cannot replace the direct methods at meat inspection because it can fail to detect early or very late stages of infections (Gamble et al. 2004). Infection levels as low as one larva/100 g of tissue is detectable by ELISA in pigs (Gamble et al., 2004). This high level of sensitivity makes serological testing by ELISA a useful method for detecting ongoing transmission of Trichinella infection at the farm or for more broadly based surveillance programmes. A disadvantage of serology for the detection of trichinellosis is the low rate of false-negative results observed in infected animals (OIE, 2012). For this reason, serological methods are not recommended for individual carcass testing. Serological responses in pigs persist for a long time after infection with no decline in titre; however, antibody has been reported to reject in horses within a few months following infection. The use of ELISA to detect the presence of parasite-specific antibodies provides a quick method that can be performed on serum, blood or tissue fluid collected before or after slaughter. The dilution used is different for serum than for tissue fluid (Nöckler et al., 2000). Antigens that are specifically secreted from the stichocytne cells of living L1 larvae and bear the TSL-1 carbohydrate epitope are recognised by Trichiella-infected animals. The specificity and sensitivity of ELISA is largely dependent on the quality of the antigen used in the test (Forbes et al., 2004; OIE, 2012).

Molecular technique. Since there are no morphological features to specify larvae, molecular diagnosis is used to yield the species or genotype diagnostically recovered. For this purpose, a multiplex PCR has been developed for the simple and unequivocal differentiation of Trichinella species and genotypes (Zarlenga, 1999). Polymerase chain reaction limited studies have shown that PCR can be used to detect the nucleic acid of larvae in the musculature of infected animals (Zarlenga et al., 2003). However, this method lacks sensitivity and is not practical for routine testing of food animals. Identification of the species or genotype of Trichinella recovered from muscle tissue is useful in understanding the epidemiology of the parasite in animals, in assessing the relative risk of human exposure and to trace back the infection to the farm of origin (OIE Terrestrial Manual, 2012). Specific primers have been developed that allow the identification of single larva collected from muscle tissues at the species and genotype level by PCR). This multiplex PCR is a sensitive, inexpensive, and rapid molecular approach that can unequivocally identify a single larva at the species and genotype levels (Pozio et al., 2003).

\section{Status of Trichinellosis in Ethiopia}

At least two confirmed outbreaks of trichnellosis had been reported in Ethiopia. One of the outbreaks was reported in Gojjam administrative region. The outbreak was associated with ingestion of meat from a wild boar. In this outbreak, from 30 soldiers, 20 who ate the raw meat became ill and 5 of them were admitted to Hospital with distinctive history and clinical features the disease. The diagnosis was confirmed by deltoid muscle biopsy in all the 5 cases. Similar outbreak had been reported from Central Arsi (Kefenie et al., 1988; Kefenie and Bero, 1992).

\section{Public health importance of trichinella}

In humans, trichinosis is an important food-borne disease that can cause acute and chronic illness. Humans are only infected with Trichinella larvae through the ingestion of meat that has not been appropriately cooked. All species of Trichinella, except for the none encapsulated species (T. pseudospiralis, T. papuae, and T. zimbabwensis), can be highly 
pathogenic in humans (Kociecka, 2000). T. spiralis is apparently more pathogenic in humans than other species because more larvae are produced by the female worms (Foreyt, 2013). Recently, T. papuae has been implicated in outbreaks of human trichinosis (Khumjui et al, 2008) .Clinical manifestations are often complex, and they depend on the age of the human host, the state of resistance, and the numbers of larvae ingested. Most clinical symptoms are present between 1 and 6 weeks after infection and the psychological effects of affected humans advance complicate the physical symptoms of the disease. Three stages of disease in humans have been described: the enteral or intestinal phase, the migratory or mucosal invasion phase, and the parenteral or convalescence phase (Foreyt, 2013).

Recently, T. papuae has been implicated in outbreaks of human trichinosis. Twenty-eight people in Thailand became sick after eating wild boar and suffered symptoms of trichinosis, and $T$. papuae was identified in a muscle biopsy from one of the patients (Khumjui et al., 2008). T. papuae was also suspected as the cause of an outbreak of trichinosis in eight people who had eaten raw soft-shelled turtles in Taiwan (Lo et al., 2009).

\section{CONCLUSION AND RECOMMENDATION}

Trichinellosis (trichinosis) is caused by nematodes (roundworms) of the genus Trichinella. The disease has a significant public health importance. All mammals are susceptible to infection, but the number of larvae required for infection varies according to the genetic constitute of the parasite and the host species. Trichinellosis is acquired by eating raw or undercooked meat that contains Trichinella larvae. Domestic animals can be infected by the consumption of infected raw tissues. Trichinella has a direct life cycle, which means it completes all stages of maturity in one host. Transmission from one host to another host can only occur by ingestion of muscle tissue which is infected with the encysted larval stage of the parasite. When ingested, muscle larvae excyst and enter tissues of the small intestine, where they undergo development to the adult stage. Male and female adult parasites mate and produce newborn larvae which leave the intestine and migrate, through the circulatory system, to striated muscle tissue. The severity of human trichinellosis is dependent upon the number of infected larvae ingested, the species of Trichinella, and the immune status of the human host. Muscle biopsy, ELISA and PCR method is important tool for diagnosis of infection.

Based on above conclusion the following recommendations are forwarded: 1) Education of the consumer about the risk of consumption of raw or undercooked meat and meat products from both domestic and wild pigs should be emphasized; 2) Strict quarantine should be exercised to control the slaughter and meat distribution of potentially infected animals.

\section{DECLARATIONS}

Corresponding Author

E-mail: Yayeh.mulu@gmail.com

\section{Consent to publish}

Not applicable.

\section{Competing interests}

The authors declare that they have no competing interests.

\section{Authors' contributions}

M. Yayeh and M. Birhan conceived the study, coordinated the overall activity, and carried out the statistical analysis, drafted the manuscript. M. Birhan participated in drafting and reviewing the manuscript. M. Yayeh and M. Birhan conceived the study, coordinated the overall activity, and reviewed the manuscript. M. Yayeh and M. Birhan participated in drafting and reviewing the manuscript. All authors read and approved the final manuscript.

Availability of data and materials

Data will be made available up on request of the primary author.

\section{Acknowledgment}

The authors' heartfelt thanks University of Gondar, Research and Community Service V/ President Office for finance and resource supporting.

\section{REFERENCES}

Azim S, Dojki.F, Ahmad.S, Beg M (2008). Role of human behaviour and parasitic diseases. Infectious Disease Journal Parasite. 17: 128 134. Google Scholar

Blaga R, Durand S, Antoniu C, Gherman M, Cretu V, Cozma and Boireau A (2007). Dramatic increase in the incidence of human trichinellosisin Romania over the past 25 years: impact of political changes andregional food habits. The American journal of tropical medicine and hygiene, 76 (5), 983-986. DOI: https://doi.org/10.4269/ajtmh.2007.76.983 I Google Scholar

Boireau P, Vallee I, Roman T, Perret C, Mingyuan L, Gamble HR, Gajadhar A. (2000). Trichinella in horses: a low frequency infection with high human risk. Veterinary Parasitology. 93(3-4):309-20. DOI: https://doi.org/10.1016/S0304-4017(00)00348-4 I Google Scholar 
Bruschi F, Murrell KD (2002) New aspects of human trichinellosis: the impact of new Trichinella species. Postgraduate Medical Journal. 78(915):15-22. http://dx.doi.org/10.1136/pmj.78.915.15 I Google Scholar

Burke R, Masuoka P, Murrell D Swine Trichinella infection and geographic information system tools. Emerg Infect Dis;14: 1109-11.

Burke R, Masuoka P, Murrell KD (2008) Swine Trichinella infection and geographic information system tools. Emerging Infectious Diseases. 14(7):1109. DOI: https://dx.doi.org/10.3201\%2Feid1407.071538 I PMCID: PMC2600339 I Google Scholar

Chomel BB. (2008) Control and prevention of emerging parasitic zoonoses. International Journal for Parasitology. 38(11):1211-7. https://doi.org/10.1016/j.ijpara.2008.05.001 I Google Scholar

Dick TA and Pozio E (2001). Trichinella spp. and trichinellosis, in Samuel, W.M., Pybus, M.J., and Ko can, A.A., eds., Parasitic diseases of wild mammals: Ames, lowa State University Press, 2: 380-396.36 https://doi.org/10.1002/9780470377000.ch15 I Google $\underline{\text { Scholar }}$

Dupouy-Camet J and Bruschi J (2007). Management and diagnosis of human trichinellosis, p. 37-68. Link I Google Scholar

Dupouy-Camet J. (2000). Trichinellosis: a worldwide zoonosis. Veterinary Parasitology. 93(3-4):191-200. https://doi.org/10.1016/S03044017(00)00341-1 I Google Scholar

Dworkin MS, Gamble HR, Zarlenga DS, Tennican PO. (1996). Outbreak of trichinellosis associated with eating cougar jerky. Journal of infectious diseases. 174(3):663-6. https://doi.org/10.1093/infdis/174.3.663 I Google Scholar

Forbes LB, Appleyard GD, Gajadhar AA. (2004). Comparison of synthetic tyvelose antigen with excretory-secretory antigen for the detection of trichinellosis in swine using enzyme-linked immunosorbent assay. Journal of Parasitology. 90(4):835-40. https://doi.org/10.1645/GE-187R I Google Scholar

Foreyt WJ. (2013). Trichinosis: Reston Va. US. Geological Survey Circular. 2013; 1388(60):2. http://dx.doi.org/10.3133/cir1388 I Google Scholar

Gajadhar AA, Scandrett WB, Forbes LB. (2006). Overview of food-and water-borne zoonotic parasites at the farm level. Revue scientifique et technique (International Office of Epizootics). 25(2): 595-606. PMID: 17094700 I Google Scholar

Gamble HR, Bessonov AS, Cuperlovic K, Gajadhar AA, Van Knapen F, Noeckler K, Schenone H, Zhu X. (2000). International Commission on Trichinellosis: recommendations on methods for the control of Trichinella in domestic and wild animals intended for human consumption. Veterinary Parasitology. 93(3-4): 393-408. https://doi.org/10.1016/S0304-4017(00)00354-X I Google Scholar

Gamble HR, Pozio E, Bruschi F, Nöckler K, Kapel CM, Gajadhar AA. (2004). International Commission on Trichinellosis: recommendations on the use of serological tests for the detection of Trichinella infection in animals and man. Parasite. 11(1):3-13. https://doi.org/10.1051/parasite/20041113 I Google Scholar

Gottstein B, Pozio E, Nöckler K. (2009). Epidemiology, diagnosis, treatment, and control of trichinellosis. Clinical microbiology reviews. 22(1): 127-45. DOI: https://doi.org/10.1128/CMR.00026-08 I Google Scholar

Goyal PK, Wheatcroft J, Wakelin D. Tyvelose and protective responses to the intestinal stages of Trichinella spiralis. Parasitology international. 51(1): 91-8. https://doi.org/10.1016/S1383-5769(02)00002-8 I Google Scholar

Hewitson JP, Grainger JR, Maizels RM. (2009). Helminth immunoregulation: the role of parasite secreted proteins in modulating host immunity. Molecular and Biochemical Parasitology. 167(1):1-1. https://doi.org/10.1016/j.molbiopara.2009.04.008 I Google $\underline{\text { Scholar }}$

Jongwutiwes S, Chantachum N, Kraivichian P, Siriyasatien P, Putaporntip C, Tamburrini A, La Rosa G, Sreesunpasirikul C, Yingyourd P, Pozio E. (1998). First outbreak of human trichinellosis caused by Trichinella pseudospiralis. Clinical Infectious Diseases. 26(1):111-5. https://doi.org/10.1086/516278 I Google Scholar

Kefenie H, Bero G. (1992). Trichinosis from wild boar meat in Gojjam, north-west Ethiopia. Tropical and geographical medicine. 44(3):27880. PMID: 1455537 I Google Scholar

Kefenie H, Wolde H, Abuherpo M. (1988) Trichinosis from wild boar meat in Arsi, central Ethiopia. Ethiopian medical journal. $26(2)$ : 97. PMID: 3360005 I Google Scholar

Khumjui C, Choomkasien P, Dekumyoy P, Kusolsuk T, Kongkaew W, Chalamaat M, and Jones L (2008) Outbreak of trichinellosis caused by Trichinella papuae, Thailand, 2006: Emerging Infectious Diseases. 14(12): 1913-1915. doi: https://doi.org/10.3201/eid1412.080800 I Google Scholar

Kocięcka W. (2000). Trichinellosis: human disease, diagnosis and treatment. Veterinary parasitology. 93(3-4):365-83. https://doi.org/10.1016/S0304-4017(00)00352-6 I Google Scholar

La Rosa G, Marucci G, Zarlenga DS, Pozio E. (2001). Trichinella pseudospiralis populations of the Palearctic region and their relationship with populations of the Nearctic and Australian regions. International journal for parasitology. 31(3):297-305. https://doi.org/10.1016/S0020-7519(01)00110-2

Lo C, Hung C, Lai S, Wu Z, Nagano I, Maeda T, Takahashi Y, Chiu H, and Jiang S Human trichinosis after consumption of soft-shelled turtles, Taiwan: Emerging Infectious Diseases, v. 15, p. 2056-2058.

Lo YC, Hung CC, Lai CS, Wu Z, Nagano I, Maeda T, Takahashi Y, Chiu CH, Jiang DD. (2009). Human trichinosis after consumption of softshelled turtles, Taiwan. Emerging Infectious Diseases. 15(12): 2056. DOI: https://doi.org/10.3201/eid1512.090619 I Google Scholar

Macpherson CN. Human behaviour and the epidemiology of parasitic zoonoses. International journal for parasitology. 35(11-12): 1319-31. https://doi.org/10.1016/j.ijpara.2005.06.004 I Google Scholar

Malakauskas A and Kapel 0 (1999). Tolerance to low temperatures of domestic and sylvatic differentiation of all encapsulated and nonencapsulated genotypes of Trichinella. International Journal of Parasitology, 29, 1859-1867.

Malakauskas A, Kapel CM. (2003) Tolerance to low temperatures of domestic and sylvatic Trichinella spp. in rat muscle tissue. The Journal of parasitology. 89: 744- 748. Google Scholar

Malakauskas A, Kapel CM. (2003). Tolerance to low temperatures of domestic and sylvatic Trichinella spp. in rat muscle tissue. The Journal of Parasitology. 89: 744-8. Google Scholar 
Murrell KD, Lichtenfels RJ, Zarlenga DS, Pozio E. (2000). The systematics of the genus Trichinella with a key to species. Veterinary Parasitology. 93(3-4):293-307. https://doi.org/10.1016/S0304-4017(00)00347-2 I Google Scholar

Nöckler K, Pozio E, Voigt WP, Heidrich J. (2000). Detection of Trichinella infection in food animals. Veterinary Parasitology. 93(3-4):335-50. https://doi.org/10.1016/S0304-4017(00)00350-2 I Google Scholar

OIE, Organization international epizootics (2012). Trichinellosis Terrestrial Manual, Pp 4-7.

Oivanen L. (2005). Endemic trichinellosis: Experimental and epidemiological studies. pp 1-82 DVM thesis Helsinki. Google Scholar

Ortega-Pierres MG, Arriaga C, Yepez-Mulia L. (2000). Epidemiology of trichinellosis in Mexico, Central and South America. Veterinary Parasitology. 93(3-4):201-25. https://doi.org/10.1016/S0304-4017(00)00342-3 I Google Scholar

Pozio $E$ and Bruschi $F$ (2001). The importance of correct terminology in describing the muscular stage of Trichinella infection. Trends in parasitology. 17(8):362. DOI: https://doi.org/10.1016/S1471-4922(01)01982-1 I PMID: 11685893 I Google Scholar

Pozio E, Hoberg E, La Rosa G, Zarlenga DS. (2009). Molecular taxonomy, phylogeny and biogeography of nematodes belonging to the Trichinella genus. Infection, Genetics and Evolution. 9(4):606-16. https://doi.org/10.1016/j.meegid.2009.03.003 I Google Scholar

Pozio E, Kapel C M O, Gajadhar A A, Boireau P, Dupouy-Camet J, Gamble H R. (2006). Trichinella in pork: current knowledge on the suitability of freezing as a public health measure. Euro Surveill. 2006;11(46):pii=3079. https://doi.org/10.2807/esw.11.46.03079en I Google Scholar

Pozio E, La Rosa G. (2000). Trichinella murrelli $n$. sp: etiological agent of sylvatic trichinellosis in temperate areas of North America. Journal of Parasitology. 86(1):134-9. https://doi.org/10.1645/0022-3395(2000)086[0134:TMNSEA]2.0.C0;2 I Google Scholar

Pozio E, La Rosa G. (2003). PCR-derived methods for the identification of Trichinella parasites from animal and human samples. PCR detection of microbial pathogens. 216: 299-309. Humana Press. Print ISBN: 978-1-58829-049-6. DOI: https://doi.org/10.1385/159259-344-5:299 I Google Scholar

Pozio E, Marucci G, Casulli A, Sacchi L, Mukaratirwa S, Foggin CM, La Rosa G. (2004). Trichinella papuae and Trichinella zimbabwensis induce infection in experimentally infected varans, caimans, pythons and turtles. Parasitology. 128(3):333-42. DOI: https://doi.org/10.1017/S0031182003004542 I Google Scholar

Pozio E, Murrell KD. (2006) Systematics and epidemiology of Trichinella. Advances in parasitology. 63:367-439. https://doi.org/10.1016/S0065-308X(06)63005-4 I Google Scholar

Pozio E, Rinaldi L, Marucci G, Musella V, Galati F, Cringoli G, Boireau P, La Rosa G. (2009). Hosts and habitats of Trichinella spiralis and Trichinella britovi in Europe. International journal for parasitology. 39(1):71-9. https://doi.org/10.1016/i.ijpara.2008.06.006 I Google Scholar

Pozio E, Zarlenga DS. (2005). Recent advances on the taxonomy, systematics and epidemiology of Trichinella. International journal for parasitology. 35(11-12):1191-204. https://doi.org/10.1016/j.ijpara.2005.07.012 I Google Scholar

Pozio E, Zarlenga DS. (2013). New pieces of the Trichinella puzzle. International journal for parasitology. 43(12-13):983-97. https://doi.org/10.1016/i.ijpara.2013.05.010 I Google Scholar

Pozio L., Rinaldi G, Marucci V, Musella F, Galati G, Cringoli P, Boireau and La Rosa Hosts and habitats of Trichinella spiralis and Trichinella britovi in Europe. Int. J. Parasitol. 10.1016/j. ijpara.2008.06.006

Pozio E and Zarlenga $S$ new pieces of the Trichinella puzzle.Int.J.Parasitol.43, 983-997

Sun GG, Wang ZQ, Liu CY, Jiang P, Liu RD, Wen H, Qi X, Wang L, Cui J. Early serodiagnosis of trichinellosis by ELISA using excretorysecretory antigens of Trichinella spiralis adult worms. Parasites \& Vectors. 8(1):484. DOI: https://doi.org/10.1186/s13071-0151094-9 I Google Scholar

Vercammen F, Vervaeke M, Dorny P, Brandt J, Brochier B, Geerts S, Verhagen R. (2002). Survey for Trichinella spp. in red foxes (Vulpes vulpes) in Belgium. Veterinary parasitology. 103(1-2):83-8. https://doi.org/10.1016/S0304-4017(01)00579-9 I Google Scholar

Webster P, Malakauskas A, Kapel CM. (2002). Infectivity of Trichinella papuae for experimentally infected red foxes (Vulpes vulpes). Veterinary parasitology. 105(3):215-8. https://doi.org/10.1016/S0304-4017(02)00022-5 I Google Scholar

Zarlenga DS, Chute MB, Martin A, Kapel CM. (1999). A multiplex PCR for unequivocal differentiation of all encapsulated and nonencapsulated genotypes of Trichinella. International Journal for Parasitology. 29(11):1859-1867. DOI: http://dx.doi.org/10.1016/s0020-7519(99)00107-1 I Google Scholar

Zarlenga DS, Rosenthal BM, La Rosa G, Pozio E, Hoberg EP (2006). Post-Miocene expansion, colonization, and host switching drove speciation among extant nematodes of the archaic genus Trichinella. Proceedings of the National Academy of Sciences. 103(19):7354-7359. https://doi.org/10.1073/pnas.0602466103 I Google Scholar

Zarlenga S, Chute B, Martin A and Kapel O (2003). A multiplex PCR for unequivocal Trichinella zimbabwensis n.sp. (Nematoda), a new nonencapsulated species from Trichinella spp. in rat muscle tissue. J Parasitol, 89, 744-748 